\title{
Orofacial Pain: A Review
}

Ragini Gupta, Vinay Mohan, Pooja Mahay and Pramod Kumar Yadav*

Department of Periodontics and Community Dentistry, Dr. Z A Dental College, Aligarh Muslim University, Aligarh, Uttar Pradesh, India

*Corresponding author: Dr. Pramod Kumar Yadav, Assistant Professor, Department of Periodontics and Community Dentistry, Dr. Z A Dental College, Aligarh Muslim University, Aligarh, Uttar Pradesh, 202001, India, Tel: +91-9935309902, +91-7275021552; E-mail: pramod468@gmail.com

Rec date: Jun 01, 2015; Acc date: Mar 04, 2016; Pub date: Mar 11, 2016

Copyright: () 2016 Gupta R, et al. This is an open-access article distributed under the terms of the Creative Commons Attribution License, which permits unrestricted use, distribution, and reproduction in any medium, provided the original author and source are credited.

\begin{abstract}
Orofacial pain is the field of dentistry devoted to the diagnosis and management of chronic, complex, facial pain and oromotor disorders. This specialty in dentistry has developed over a number of years out of the need for better understanding of a group of patients who somehow were not clearly suffering from dental pain disorders. Orofacial pain represents a significant burden in terms of morbidity and health service utilization. It includes very common disorders such as toothache and temporomandibular disorders, as well as rare orofacial pain syndromes. Many orofacial pain conditions have overlapping presentations, and diagnostic uncertainty is frequently encountered in clinical practice. Our profession has realized the importance of basic knowledge and differential diagnosis in order to manage these patients properly. This modification in the approach has caused several changes in education as well as in clinical activities. This paper aims to discuss the importance of basic knowledge to perform successful management.
\end{abstract}

Keywords: Pain; Orofacial; Pain assessment; Orofacial pain therapy

\section{Introduction}

Orofacial pain is a general term covering any pain, which is felt in the mouth, jaws and the face. Different individuals sensing identical noxious stimulation feel pain in different ways and react at different levels of suffering [1]. In 1986, according to the Nuprin pain report of the 1254 persons questioned, $27 \%$ reported having experienced dental pain and $73 \%$ reported headache during the previous 12 months. $12 \%$ of the patients who reported headache sought cause for the pain from a dental practitioner. This report indicates that the task of managing head and neck pain is a very real one indeed [2].

In recent years there has been an increase in professional interest in orofacial pain disorders. A new type of clinical field is emerging with unique experience in managing orofacial pain disorders. It suggests that pain is mediated by way of specialized neural structures that are made for that purpose and indicates that pain is a protective mechanism against injury [1].

IASP (International association for Study of Pain) defines pain as 'an unpleasant sensory and emotional experience associated with actual or potential tissue damage or described in term of such damage' [3]. It can also be defined as an unpleasant emotional experience usually initiated by noxious stimulus and transmitted over a specialized neural network to the CNS where it is interpreted as such' [4].

\section{Cranial Nerves (Origin, Pathways and Applied Anatomy)}

There are twelve cranial nerves, which leave the brain and pass through foramina in the skull. All the nerves are distributed in the head and neck except the tenth, which also supplies structures in the thorax and abdomen (Table 1) [5,6].

\section{Trigeminal nerve}

The trigeminal $(\mathrm{CN}-\mathrm{V})$, the largest cranial nerve, is the sensory supply to face, the greater part of the scalp, the teeth, the oral and nasal cavities and the motor supply to the masticatory and some other muscles. It also contains proprioceptive fibers from the masticatory and extraocular muscles.

It has three divisions namely ophthalmic, maxillary and mandibular. It emerges from pons as a larger sensory and a smaller motor root. Fibers in the sensory root are mainly axons of cells in the trigeminal ganglion, which occupies trigeminal cave. The neuritis of the unipolar cells in ganglion divides into peripheral and central processes. The peripheral branches constitute the ophthalmic, maxillary and sensory parts of the mandibular nerve. The central branches constitute the fibers of the sensory root, which ends in the pons [7].

Ophthalmic division: It exits the cranial cavity through the superior orbital fissure. The recurrent branch supplies the anterior cranial fossa and the tentorium cerebelli (meningeal fold above the posterior cranial fossa) [8].

Maxillary division: It exits the cranial cavity through the foramen rotundum. The recurrent branch supplies the anterior part of the middle cranial fossa. The maxillary nerve goes to the nasal region (pterygopalatine fossa) where it is joined by hitchhikers from the facial nerve (pterygopalatine ganglion). These parasympathetic and taste nerves supply the palatine, nasal and lachrymal glands and get there by hitchhiking with most of the branches of the maxillary nerve [9].

Mandibular division: It exits the cranial cavity through the foramen ovale. A recurrent meningeal branch goes back into the cranial cavity to supply the middle cranial fossa and inside the temporal region $[4,7,8]$.

In the infratemporal region the mandibular nerve has motor branches to all the muscles of mastication (temporalis, masseter, medial pterygoid, lateral pterygoid) plus also the anterior belly of digastric, tensor palate and tensor tympani (in the middle ear) [5,9]. 
The sensory branches include auriculotemporal, buccal, lingual and inferior alveolar nerve.

\begin{tabular}{|c|c|c|}
\hline S.No & Cranial Nerve & Function \\
\hline I & Olfactory & Sense of smell \\
\hline II & Optic & Visual acuity, visual fields \\
\hline III & Oculomotor & Movement of eyeball, pupil and upper eyelid \\
\hline IV & Trochlear & Eye movement \\
\hline V & Trigeminal & $\begin{array}{l}\text { Tactile facial sensation, motor innervation of } \\
\text { muscles of mastication, corneal reflex }\end{array}$ \\
\hline VI & Abducens & Lateral movements of the eyes \\
\hline VII & Facial & $\begin{array}{l}\text { Movements of facial muscles extrinsic and } \\
\text { intrinsic ear muscles taste (anterior two thirds of } \\
\text { tongue) }\end{array}$ \\
\hline VIII & Acoustic Vestibular & $\begin{array}{l}\text { Hearing, equilibrium and orientation of head in } \\
\text { space }\end{array}$ \\
\hline IX & Glossopharyngeal & $\begin{array}{l}\text { Elevation of palate, movement of pharynx and } \\
\text { larynx. General sensation from palate, posterior } \\
\text { one third of tongue and oropharynx. Taste from } \\
\text { posterior one third of tongue and oropharynx. }\end{array}$ \\
\hline $\mathrm{x}$ & Vagus & $\begin{array}{l}\text { Muscles of soft palate, base of tongue, pharynx, } \\
\text { larynx. Parasympathetic fibres to thoracic and } \\
\text { abdominal viscera }\end{array}$ \\
\hline $\mathrm{XI}$ & Accessory & $\begin{array}{l}\text { Movement of sternocleidomastoid and trapezius } \\
\text { muscles }\end{array}$ \\
\hline XII & Hypoglossal & Movement of tongue \\
\hline
\end{tabular}

Table 1: Function of cranial nerves.

\section{Classification of Orofacial Pain} [7]

Orofacial pain can be classified into following different categories

\section{Neuralgias}

- Primary Trigeminal Neuralgia (Tic Douloureux)

- Secondary Trigeminal Neuralgia (CNS Lesion or facial trauma)

- Herpes Zoster

- Post Herpetic Neuralgia

- Geniculate Neuralgia (Cranial Nerve VII)

- Glossopharyngeal Neuralgia (Cranial Nerve IX)

- Superior Laryngeal Neuralgia (Cranial Nerve X)

- Occipital Neuralgia

\section{Pain of musculoskeletal origin}

- Cervical Osteoarthritis

- Temporomandibular joint disorders

- TMJ Rheumatoid arthritis

- TMJ Osteoarthritis

- Myofacial Pain Dysfunction

- Fibromyalgia

- Cervical Sprain or Hyperextension

- Stylohyoid (Eagle's) Syndrome

\section{Primary vascular disorders}

- Migraine with aura

- Migraine without aura

- Cluster Headache

- Tension-type Headache

- Hypertensive Vascular changes (Aneurysm, Emboli)

- Mixed Headache

- Cranial ateritis

- Carotodynia

- Thrombophlebitis

\section{Psychogenic pains}

- Delusional/hallucinatory

- Hysterical/Hypochondriac

\section{Generalised pain syndromes}

- Post-traumatic pains

- Sympathetically maintained pain (Causalgia)

- Phantom Pain

- Central Pain

\section{Lesions of the ear, nose, and oral cavity}

- Maxillary Sinusitis

- Otitis media

- Odontalgia

- Dentin defects

- Pulpitis

- Periapical pathology/Abscess

- Cracked tooth/restoration

- Atypical odontalgia

- Periodontal pathology

- Occlusal trauma

- Dental impaction

- Cysts and tumors

- Osteitis

- Mucocuteneous diseases

- Salivary gland diseases

- Atypical facial pain

- Glossodynia

\section{Epidemiology}

Numerous reports in the scientific literature have attempted to identify the epidemiology of orofacial pain. The 1986 Nuprin Pain Report noted that most Americans experience an average of three or four different kinds of pain annually [8]. Crook et al. reported that $16 \%$ of the general population suffered pain within a 2 week period [10]. James et al. reported that more than $81 \%$ of the population reported a significant jaw pain experience over the course of their life-time [11]. Lipton et al. noted in 1993 that 22\% of Americans reported orofacial pain within 6 month period. Although the orofacial pain most commonly experienced by patients and encountered by oral health care providers in toothache, it seldom seems to be an isolated complaint $[12,13]$. Turp et al. noted that more than $81 \%$ of patients 
Page 3 of 6

reporting to an orofacial pain centre had pain sources beyond the trigeminal system [14].

\section{Pain diagnosis}

The most important part of managing orofacial pain is in understanding the problem and arriving at a proper diagnosis. It is only by proper diagnosis that an appropriate treatment can be selected. The objective of diagnosis is to accurately identify the what, where, how and why of the patients complaints. The characteristics of pain make diagnosing the pain more difficult [3].

- Diagnosing a pain complaint consists of these major steps [3]

- History

- Clinical examination

- Accurately identifying the location of the extractions from which the pain emanates

- Establishing the correct pain category that is represented in the condition under investigation

Choosing the particular pain disorder that correct accounts for the incidence and behavior of the patients pain problem

\section{Assessment of pain}

In the assessment of pain intensity, rating scale techniques are often used. The most commonly used techniques are:

- Numerical Rating Scale

- Visual Analogue Scale

- McGill Pain Questionnaire

- Behavioral Rating Scale

Numerical Rating Scale (NRS): The numerical pain rating scale (NRS), on which patients rate their current pain intensity from 0 ("no pain") to 10 ("worst possible pain"), has become the most widely used instrument for pain screening as it is easy to use. It is shown in Figure 1 $[1,3,4,15]$.

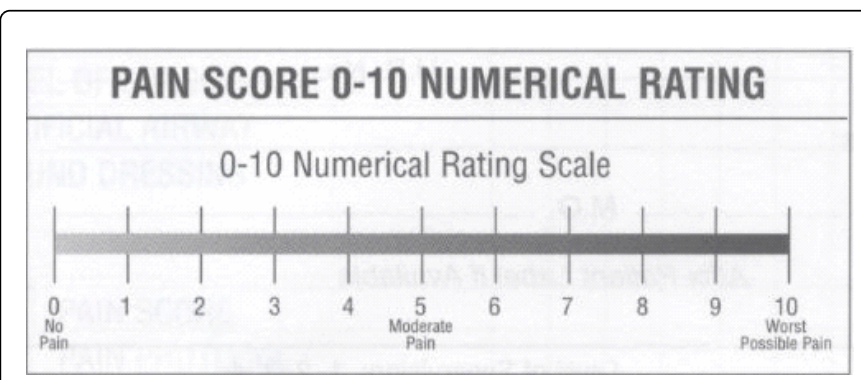

Figure 1: Numerical Rating Scale.

Visual Analogue Scales (VAS): It consists of a $10 \mathrm{~cm}$ line with anchor points at each end. The VAS has been shown to be more sensitive to change and is therefore more widely used. These scales may also be incorporated into pain diaries, and is shown in Figure $2[3,16]$.

McGill Pain Questionnaire (MPQ): It is also known as McGill pain index, is a scale of rating pain developed at McGill University by Melzack and Torgerson in 1971. It is a self-report questionnaire that allows individuals to give their doctor a good description of the quality and intensity of pain that they are experiencing. It is a very widely used questionnaire. 78 pain adjectives are arranged into 20 groups that are further arranged into sets of words describing sensory aspects of the quality of pain. This is shown in Figure $3[3,16]$.
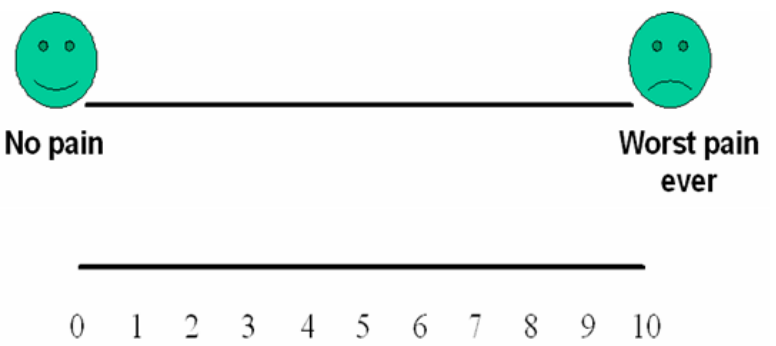

Figure 2: Visual Analogue Scale.

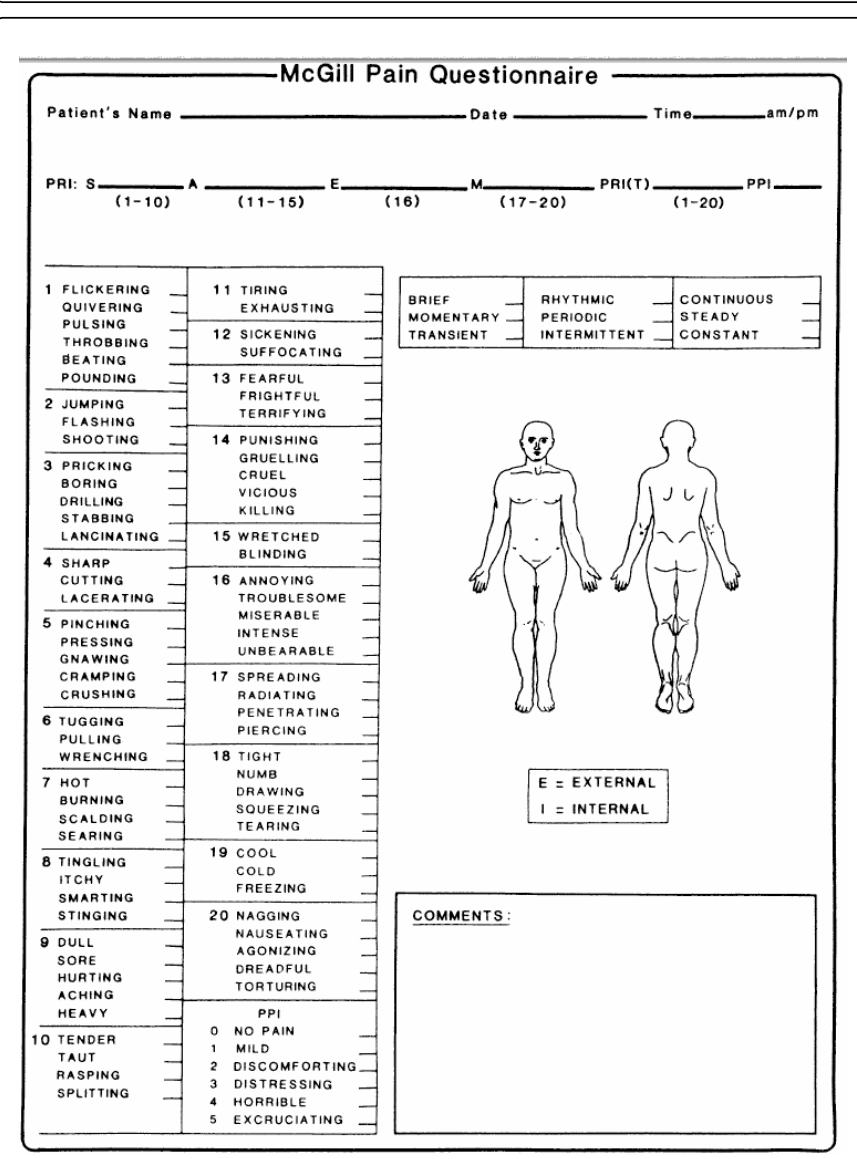

Figure 3: McGill Pain Questionnaire.

Behavioral rating scale: For patients unable to provide a self-report of pain, a score from 0 to 10 is assigned based on clinical observation (Table 2).

\section{Other diagnostic methods}

Imaging: Imaging can be used to confirm a suspected abnormality, to screen and rule out possible abnormalities that are not detectable by other methods or to establish the extent of an identified disorder. It is 
Page 4 of 6

the best method to evaluate a suspected tumor, infection, or inflammation. Many disorders do not produce abnormality clinically but may be demonstrated with imaging and hence its greatest value may be rule out serious life threatening diseases [1].

\begin{tabular}{|c|c|c|c|c|}
\hline \multirow[b]{2}{*}{ Face } & 0 & 1 & 2 & \multirow[b]{2}{*}{ Face score: } \\
\hline & $\begin{array}{l}\text { Face muscles } \\
\text { relaxed }\end{array}$ & $\begin{array}{l}\text { Facial } \\
\text { muscle } \\
\text { tension, } \\
\text { frown, } \\
\text { grimace }\end{array}$ & $\begin{array}{c}\text { Frequent to } \\
\text { constant } \\
\text { frown, } \\
\text { clenched jaw }\end{array}$ & \\
\hline \multirow[b]{2}{*}{ Restlessness } & 0 & 1 & 2 & \multirow[b]{2}{*}{$\begin{array}{c}\text { Restlessness } \\
\text { score: }\end{array}$} \\
\hline & $\begin{array}{c}\text { Quiet, } \\
\text { relaxed } \\
\text { appearance, } \\
\text { normal } \\
\text { movement }\end{array}$ & $\begin{array}{l}\text { Occasional } \\
\text { restless } \\
\text { movement, } \\
\text { shifting } \\
\text { position }\end{array}$ & $\begin{array}{l}\text { Frequent } \\
\text { restless } \\
\text { movement } \\
\text { may include } \\
\text { extremities } \\
\text { or head }\end{array}$ & \\
\hline \multirow[b]{2}{*}{ Muscle tone* } & 0 & 1 & 2 & \multirow[b]{2}{*}{$\begin{array}{c}\text { Muscle tone } \\
\text { score: }\end{array}$} \\
\hline & $\begin{array}{c}\text { Normal } \\
\text { muscle tone }\end{array}$ & $\begin{array}{l}\text { Increased } \\
\text { tone, flexion } \\
\text { of fingers } \\
\text { and toes }\end{array}$ & Rigid tone & \\
\hline \multirow[b]{2}{*}{ Vocalisation** } & 0 & 1 & 2 & \multirow[b]{2}{*}{$\begin{array}{l}\text { Vocalisation } \\
\text { score: }\end{array}$} \\
\hline & $\begin{array}{l}\text { No abnormal } \\
\text { sounds }\end{array}$ & $\begin{array}{l}\text { Occasional } \\
\text { moans, } \\
\text { cries, } \\
\text { whimpers } \\
\text { and grunts }\end{array}$ & $\begin{array}{l}\text { Frequent or } \\
\text { continuous } \\
\text { moans, } \\
\text { cries, } \\
\text { whimpers or } \\
\text { grunts }\end{array}$ & \\
\hline \multirow[b]{2}{*}{ Consolability } & 0 & 1 & 2 & \multirow[b]{2}{*}{$\begin{array}{c}\text { Consolability } \\
\text { score: }\end{array}$} \\
\hline & $\begin{array}{l}\text { Content, } \\
\text { relaxed }\end{array}$ & $\begin{array}{l}\text { Reassured } \\
\text { by touch, } \\
\text { distractible }\end{array}$ & $\begin{array}{l}\text { Difficult to } \\
\text { comfort by } \\
\text { touch or talk }\end{array}$ & \\
\hline
\end{tabular}

Behavioural pain assessment scale total $(0-10)$

$/ 10$

Table 2: Behavioral Rating Scale.

Laboratory test: When a clinician is suspicious of significant medical problems, medical laboratory testing may be needed to confirm the diagnosis. Blood studied also help to rule out other systemic infections or conditions [1].

\section{Confirmation of the clinical diagnosis}

Before undertaking a definitive therapy, confirmation of the clinical diagnosis is advisable [1]. There are 4 methods that can help the diagnosis namely

- Diagnostic analgesic blocking

- Utilization of diagnostic drugs

- Consultation

- Trial therapy

Diagnostic analgesic blocking: It is essential for differentiating primary from secondary pain and useful to identify pathways that mediate peripheral pain and localized pain source. Skillful analgesic blocking of muscles of masticatory system, maxillofacial region and TMJ are especially useful in the diagnosis of masticatory pain and nonmasticatory myofascial pain disorders [1].
Diagnostic and therapeutic anesthetic blocks are divided into:

- Muscle injections- valuable in determining the source of pain and therapeutic value [17].

- Nerve block injection- helps to identify whether the painful structure is a site or source of pain [18].

- Intracapsular injections- injections directly into the TMJ for therapeutic reasons [19].

Consultations: On occasion pain problems require medical, orolaryngologic, orthopedic, neurologist rheumatologic, or psychologic consultation for proper identification of the pain disorders [20].

Trial therapy: A short period of trial therapy is a good means of confirming a diagnosis, provided the examiner is familiar with the effects of placebo therapy. This is particularly true when the patient has Axis II disorders. Oxcarbazepine can be used to confirm a doubtful diagnosis paroxysmal surface. This mediation has no analgesic action and therefore does not relieve pain. If relief is well beyond the $40 \%$ of maximum placebo effect within a few days, it's presumptive evidence that the disorder in question is in fact paroxysmal neurologic. However absence of relief does not exclude neurologic condition [20].

\section{General Considerations in Managing Orofacial Pain}

The conditions that generate pain are susceptible to modification. The treatment of people who suffer pain entails the manipulation of those factors that initiate and accentuate pain and/or the institution of means and methods by which patients can better cope with their complaint. The pain management covers following factors [21]:

- Elimination of causative noxious stimuli

- Interception of nociceptive circuits

- Enhancement of neural mechanism of pain inhibition [17]

\section{Physical therapy}

Physical therapy modalities refer to those treatments that utilize an instrument, device or agent to accomplish the desired effect. These include sensory stimulation, ultrasound, electrogalvanic stimulation, deep heat and other methods [22].

Sensory stimulation: It can be divided into several categories according to the tissue and mode of stimulation. They include cutaneous, transcutaneous, and percutaneous stimulations [1].

Cutaneous stimulation: The effect occurs through stimulation of thick myelinated cutaneous afferents especially $\alpha$ and $\beta$ motor neurons. Other inhibitory mechanisms may also be involved.

There are many forms of cutaneous stimulants like

- Superficial massage over the site of injury is an important means of reducing pain. It is enhanced by adding a stimulating substance such as alcohol or menthol.

- Counter irritation with mustard plaster.

- Vapocoolant therapy is important in management of myofascial trigger point pain. Initially thought to be a local anesthetic, it is a mild stimulator of cutaneous nociceptor as well as $\alpha, \beta$ fibers. Thus stimulating pain inhibitory method. Ethyl chloride spray is used and its application is painful mandibular movement was introduced by Schwartz in 1954 [1]. 
- Mechanical vibration is also being used and at least one-third patients to obtain complete relief from pain and the period of relief out lasts the stimulation by several hours [22].

- Hydrotherapy is useful especially for neck and pack pains of muscular origin. Agitated circulating water and a brisk stream of lower water has a therapeutic effect [22].

Transcutaneous stimulation: It is performed by following methods.

- TENS: It utilizes a high frequency but very low intensity current. It is used to stimulate the non-nociceptive $\alpha, \beta$ cutaneous afferents that activate the descending pain inhibitory mechanism without involving opioid peptides. It is felt as a tingling or vibratory sanitation with no phasic muscle contraction, some minor tonic contraction may occur in nearby muscles. Its action is said to be immediate and generally restricted to the segment stimulated. The analgesic effect ranges from $50-70 \%$ [23].

- Electroaccupuncture (EP): It utilizes a low frequency (2H2) but high intensity electric current and is applied at specific cutaneous sites called as acupoints. It is used to stimulate muscle nociception which in turn activate the endogenous antinoccieptive mechanism. The effect is not immediate, but requires an induction period of 15 to 20 minutes. The analgesia may be either segmented or general [17].

Both TENS and EP are effective if properly applied and provide satisfactory pain relief in $50-70 \%$ of cases [23].

Percutaneous stimulation is done by placing electrodes that penetrate the skin and is used in neurosurgery. Subcutaneous nerve stimulation (SCNS) by electric current produces prolonged analgesia and tolerance is not developed [24].

\section{Thermotherapy}

Thermotherapy in rehabilitation is the therapeutic application of superficial mild heat to increase circulation, enhance healing, increase soft tissue extensibility, and control pain. In the context of pain management, potential therapeutic benefits of superficial heat are due to its effects on metabolic, neuromuscular, and hemodynamic activity [25].

\section{Cryotherapy}

In a rehabilitation context, cryotherapy withdraws heat from the body through the use of mild superficial cooling agents. It is used to control pain, edema, and inflammation; to enhance movement; and to attenuate spasticity [1].

\section{Ultrasound}

Unlike ultrasound used for medical imaging, therapeutic ultrasound is used to deliver energy to deep tissue sites, via propagation of ultrasonic waves, to produce increases in tissue temperature or nonthermal physiologic changes. Rather than transmitting ultrasonic waves through tissue and then processing a returning echo to generate an image of underlying structures, therapeutic ultrasound is one-way energy delivery [1].

\section{Diathermy}

Diathermy is the use of shortwave (wavelength 3-30 m, frequency 10-100 MHz) or microwave (wavelength $0.001-1 \mathrm{~m}$, frequency 300
$\mathrm{MHz}$ to $300 \mathrm{GHz}$ ) electromagnetic radiation to produce heat within body tissue through conversion [1].

\section{Manual techniques}

Massage: Mild stimulation of cutaneous sensory nerves exerts an inhibitory influence on pain gentle massage of tissues overlying a painful area can often reduce pain sensation [22].

Spray and stretch technique: A mixture of fluorocarbon such as fluori-methane is used as Vapocoolant. The muscle is stretched and the vapocoolant is applied by parallel sweeps in one direction traveling to pain reference area. At the end of treatment moist heat should be applied for best results. It is used to treat myofascial trigger points [26].

Exercise: Forceful contraction of antagonist muscle causes reflex relaxation of an agonist muscle and this principle is used in treatment of masticatory muscle spasm [22].

Physical activity: In patients with chronic pain, maintenance of physical activity is an important part of therapy. Patients tend to withdraw and take to their beds. Individual who maintain levels of aerobic fitness seem to feel better, sleep better and concentrate better [22].

Psychological therapy: Counseling and behavioral modification training can be employed as a part of psychological therapy [22].

- Behavioral modification training: Two types of behavior modification include stress reduction training and relaxation training.

\section{Management of Specific Orofacial Pain Disorders}

\section{Facial neuralgias}

The classic neuralgias that affect the craniofacial region are a unique group of neurologic disorders involving the cranial nerves and are characterized by (a) brief episodes of shooting, often electric shock-like pain along the course of the affected nerve branch; (b) trigger zones on the skin or mucosa that cause painful attacks when touched; and (c) pain-free periods between attacks and refractory periods immediately after an attack, during which a new episode cannot be triggered [27].

\section{Periodontal diseases}

Periodontal pockets: Management includes pocket irrigation and flap surgery

Chronic periodontitis: Management includes oral prophylaxis and flap surgery

Aggressive periodontitis: It is managed using antibiotics depending on the type of microorganisms. If microflora contains gram-positive microorganisms, then it should be treated with $250 \mathrm{mg}$ amoxicillin and $125 \mathrm{mg}$ potassium clavulunate three times daily, for 14 days, along with scaling and root planning) and if flora is gram-negative, then clindamycin should be given with doses of $150 \mathrm{mg}$, four times a day, for 7 days, along with scaling and root planning [28].

Periodontal abscess: Pain due to periodontal pain is managed using the following methods [28]

- Analgesic and antibiotics

- Incision and drainage - primary treatment for relief of acute symptoms is incision of the fluctuant abscess, from the depth of the 
Page 6 of 6

abscess cavity to the gingiva. The incision should extend into the soft tissue of the root surface.

- Debridement of root surface - if the surrounding tissue is normal, the tooth may be retained and debridement of the root surface by removal of granulation tissue should be done. Treatment and new tissue regeneration should be performed.

- Extraction of tooth - if the roots are denuded beyond the apical third of the root, the tooth should be extracted and curettage should be carried out to remove the granulation tissue from the socket.

\section{Occlusal trauma}

A goal of periodontal therapy in the treatment of occlusal trauma should be to maintain the periodontium in comfort and function. In order to achieve this goal a number of treatment considerations must be considered including one or more of the following $[28,29]$.

- Occlusal adjustment

- Management of parafunctional habits

- Temporary, provisional or long-term stabilization of mobile teeth with removable or fixed appliances

- Orthodontic tooth movement

- Occlusal reconstruction

- Extraction of selected teeth

\section{Conclusion}

Orofacial pain remains appealing yet inadequately grasped condition in field of oral medicine. Many evidences and theories are emerging in this respect lately as a result of which treatment modalities are also diversifying. As far as diagnosis of orofacial pain is concerned, explanation will be found for patient's complaint of pain. Extensive and reasonably adequate diagnostic investigations are complied, if they also fail then one should probe for mere unusual conditions, sometimes psychiatric evaluation is also recommended. Based on caring and supportive attitude, a correct patient stratification and disciplinary approach will form beneficial standards for application of current knowledge in treating orofacial pain disorders.

\section{References}

1. Okeson JP (2005) Bell's Orofacial Pain: The Clinical Management of Orofacial Pain. (6th edn.), Quintessence Publishing Co. Ltd, New Malden, Surrey.

2. Sternbach RA (1986) Survey of pain in the United States: the Nuprin pain report. Clin J Pain 2: 49-53.

3. Coffey GH, Mahon MV (1982) Pain: theories and a new approach to treatment. J Natl Med Assoc 74: 147-153.

4. Monheim LM (1983) Monheim's Local Anesthesia and Pain Control in Dental Practice. (7th edn.), Mosby, St. Louis.

5. Gray H, Williams PL, Bannister LH (1995) Gray's Anatomy: the Anatomical Basis of Medicine and Surgery. (38th edn.), Churchill Livingstone, New York.

6. Kirshenbaum D (2010) Cranial nerves, Gross Anatomy 2007. BUSM Class of 2011.
7. Greenberg MS, Glick M, Ship JA (1994) Burket's Oral medicine: Diagnosis and Treatment (9th edn.), JP Lippincott Company, Philadelphia.

8. Sternbach RA (1986) Pain and 'hassles' in the United States: findings of the Nuprin pain report. Pain 27: 69-80.

9. Abrahams PH, Marks SC Jr, Hutchings RT (2003) McMinn’s Color Atlas of Human Anatomy. (5th edn.), Mosby, New York.

10. Crook J, Tunks E, Rideout E, Browne G (1986) Epidemiologic comparison of persistent pain sufferers in a specialty pain clinic and in the community. Arch Phys Med Rehabil 67: 451-455.

11. James FR, Large RG, Bushnell JA, Wells JE (1991) Epidemiology of pain in New Zealand. Pain 44: 279-283.

12. Lipton JA, Ship JA, Larach-Robinson D (1993) Estimated prevalence and distribution of reported orofacial pain in the United States. J Am Dent Assoc 124: 115-121.

13. Von Korff M, Dworkin SF, Le Resche L, Kruger A (1988) An epidemiologic comparison of pain complaints. Pain. 32: 173-183.

14. Türp JC, Kowalski CJ, Stohler CS (1997) Temporomandibular disorderspain outside the head and face is rarely acknowledged in the chief complaint. J Prosthet Dent 78: 592-595.

15. Conti PC, Pertes RA, Heir GM, Nasri C, Cohen HV, et al. (2003) Orofacial pain: basic mechanisms and implication for successful management. J Appl Oral Sci 11: 1-7.

16. ICD-9 CM (2009).

17. Fine PG, Milano R, Hare BD (1988) The effects of myofascial trigger points injections are naloxone reversible. Pain 32: 15-20.

18. Schmidt B, Pogrel MA, Necoechea M, Kearns G (1998) The distribution of the auriculotemporal nerve around the temporomandibular joint. Oral Surg Oral Med Oral Pathol Oral Radiol Endod 86: 165-168.

19. Henny FA (1954) Intra-articular injection of hydrocortisone into the temporomandibular joint. J Oral Surg 12: 314-319.

20. Scully C, Porter S (1999) Orofacial disease: updates for the clinical team: Orofacial Pain. Dent Update 26: 410-417.

21. Degenaar JJ (1979) Some philosophical considerations on pain. Pain 7: 281-304.

22. Clark G (2008) Most medication used for orofacial medication. CDA J 36: 747-767.

23. Augustinsson LE, Bohlin P, Bundsen P, Carlsson CA, Forssman L, et al. (1977) Pain relief during delivery by transcutaneous electrical nerve stimulation. Pain 4: 59-65.

24. Hwang BC, Min BI, Kim JH, Na HS, Park DS (2002) Effects of electroacupuncture on the mechanical allodynia in the rat model of neuropathic pain. Neurosci Lett 320: 49-52.

25. de Leeuw R, Klasser G, American Academy of Orofacial Pain (2013) Orofacial Pain Guidelines for Assessment, Diagnosis and Management. (5th edn), Quintessence Publishing Co, Inc, Chicago.

26. Simons DG, Travell JG, Simons LS (1999) Apropos of all muscle. In: Travell \& Simons' Myofascial Pain and Dysfunction: The Trigger Point Manual. (2nd edn.), Williams \& Wilkins, Baltimore.

27. Burket LS, Greenberg MS, Glick M, Ship JA (2008) Burket's Oral Medicine. (11th edn.), BC Decker Inc, Hamilton.

28. Ghom AG, Ghom SA (2008) Text Book of Oral medicine. (2nd edn.), JP Medical Ltd, London.

29. American Academy of Periodontology (2000) Parameter on occlusal traumatism in patients with chronic periodontitis. J Periodontol 71 : 873-875. 